\title{
Discordance between Spinal and Hip Bone Mineral Density Values in Patients with Lumbar Scoliosis - Experience of a Single Institute
}

Shamim M F Begum, Nasreen Sultana, Zeenat Jabin, Rahima Parveen, Azmal Kabir Sarker and Layla Saroware Banu National Institute of Nuclear Medicine and Allied Sciences (NINMAS), Dhaka, Bangladesh

Correspondence Address : Prof. Dr. Shamim Momtaz Ferdousi Begum, Professor and Head, Nuclear Nephrology Division, National Institute of Nuclear Medicine \& Allied Sciences, BAEC, Email: pragyna06@yahoo.com, telephone: +880-2-9665912, mobile +880-1711849903

\begin{abstract}
Osteoporosis and scoliosis are encountered concurrently. Scoliosis predisposes to osteoporosis but degenerative scoliosis could falsely elevate lumbar bone mineral density measurement leading to discordance. This study was conducted to determine the prevalence of discordance between lumbar spines and hip bone mineral density in patients with lumbar scoliosis and to evaluate the risk factors of discordance. The prevalence of osteoporosis and discordance was determined as major and minor discordance. Old age, age at menopause, sex and BMI were considered as possible risk factors for discordance and were used in multivariate logistic regression analysis. Discordance between lumbar spines and hip was found in $55(78.6 \%)$ patients and among them major and minor discordance of $\mathbf{T}$-scores were seen in $18(25.7 \%)$ and $37(52.9 \%)$ respectively. Concordance of $\mathrm{T}$ scores was seen in $15(21.4 \%)$. In multivariate logistic regression analysis female sex, age older than 60 years and BMI less than 30 $\mathrm{kg} / \mathrm{m} 2$ was identified as risk factors for $\mathrm{T}$-score discordance.

In lumbar scoliosis the overestimation of lumbar spine may lead to diagnostic dilemma, whereas hip DEXA appears to be more reliable in these cases. In such cases it is in the jurisdiction of the physician to look for possible underlying causes of discordance of $\mathbf{T}$ score. Key words: Bone Mineral Density (BMD), Discordance and Scoliosis.
\end{abstract}

\section{INTRODUCTION}

Osteoporosis and scoliosis are frequently encountered concurrently. Osteoporosis is the world's most prevalent metabolic disease of bone and expressed as low bone mass, increased fragility, decreased bone quality and increased risk of fracture(1). Dual-energy X-ray absorptiometry (DEXA) is a routinely used, widely accepted, cost-effective method to measure bone mineral density (BMD). The World Health Organization (WHO) has established DEXA as the best densitometry technique and recognized as the reference method for assessing BMD in postmenopausal women. According to WHO diagnostic criteria, osteoporosis is defined in terms of a T-score below 2.5 and osteopenia, when $\mathrm{T}$-score is between -2.5 and -1 , normal bone density when T-score is more than -1 $(2,3)$. BMD has measured at different sites and it has been shown that although the values of different sites correlate, the agreement between these sites are low. Disagreement of T-score between lumbar spine and hip bone leads to discordance. Discordance is a commonly observed phenomenon in densitometry study and has been divided into two groups: major discordance and minor discordance. Degenerative lumbar scoliosis is one of the responsible factors for discordance in the bone mineral density values in lumbar spine and hip bone. Degeneration of the lumbar spines or lumbar spondylosis is frequently encountered in elderly persons and developed in a skeletally mature patient $(4,5)$.

It has been suggested that scoliosis predisposes to osteoporosis but degenerative scoliosis could falsely elevate lumbar bone mineral density measurement leading to discordance. When both osteoporosis and scoliosis coincide in the same person, the diagnosis of osteoporosis and treatment of spinal condition become cumbersome. The falsely elevated lumbar bone mineral density measurement even though osteoporosis is evident in the hip bone leads to diagnostic dilemma. This study was conducted to determine the prevalence of discordance between lumbar spines and hip bone mineral density in Bangladeshi patients with lumbar scoliosis in order to evaluate the risk factors of discordance. 


\section{PATIENTS AND METHODS}

This is a prospective study carried out with Norland DEXA- XR 36 machine at NINMAS of Bangbandhu Sheikh Mujib Medical University campus, Shahbag, Dhaka, over a period of eleven months between July 2014 and May 2015. Patients referred for BMD test at NINMAS and having lumbar scoliosis in DEXA scan were included in this study. A total of 70 patients were enrolled in this study. The scoliosis of lumbar spine was determined by observation from the coronal images of DEXA scan. Written informed consent was obtained from each participant and detailed history were taken and recorded. Patients having history of spine fracture or implants were excluded from this study.

The $\mathrm{T}$ scores were recorded for determining osteoporosis in lumbar spines and hip bones (Ward's triangle of femur neck). The prevalence of osteoporosis and discordance of bone density was determined as major and minor discordance. Minor discordance happens when the different diagnostic classes are adjacent, that is, patient is diagnosed as osteoporotic in one site and osteopenic in the other site, or, osteopenic in one site and normal in the other site. If the diagnosis is osteoporosis in one site and the other site is in the normal range, the discordance falls into the major group (6). The study subjects were divided again into four groups according to body mass index (BMI), i.e. low BMI or underweight group $(\leq 18.5 \mathrm{Kg} / \mathrm{m} 2)$, normal BMI or normal weight group (18.5-24.9 Kg/m2), over weight group $(25-29.9 \mathrm{Kg} / \mathrm{m} 2)$ and obese group $(\geq 30 \mathrm{Kg} / \mathrm{m} 2)$. Old age, female gender and low BMI were considered as possible risk factors for discordance and were used in multivariate logistic regression analysis.

\section{RESULTS}

Total 70 patients (M-21, F-49) with a M:F ratio of 1: 2.3 and age ranging between 42 to 88 years (mean $\pm \mathrm{SD}=$ $64.01 \pm 10.55$ ) were included (Table 1, 2). Discordance between lumbar spines and hip was found in 55 (78.6 $\%)$ patients and among them major and minor discordance of T-scores were seen in $18(25.7 \%)$ and 37
(52.9\%) respectively. Concordance of $\mathrm{T}$ scores was seen in 15 (21.4\%) (Table 3).

Table 1: Sex distribution of the patients $(n=70)$

\begin{tabular}{|l|c|c|}
\hline Sex & Frequency & Percentage \\
\hline Male & 21 & 30.0 \\
\hline Female & 49 & 70.0 \\
\hline Total & 70 & 100.0 \\
\hline Male: Female ratio & \multicolumn{2}{|c|}{$1: 2.3$} \\
\hline
\end{tabular}

Table 2: Age distribution of the patients $(n=70)$

\begin{tabular}{|l|c|c|}
\hline Age & Frequency & Percentage \\
\hline $41-50$ yrs & 10 & 14.3 \\
\hline $51-60$ yrs & 18 & 25.7 \\
\hline $61-70$ yrs & 28 & 40.0 \\
\hline $71-80$ yrs & 10 & 14.3 \\
\hline$>80$ yrs & 4 & 5.7 \\
\hline Total & 70 & 100.0 \\
\hline Mean \pm SD Range & $64.01 \pm 10.55(42-88)$ years \\
\hline
\end{tabular}

Table 3: Distribution of the patients by type discordance and concordance $(n=70)$

\begin{tabular}{|l|c|c|}
\hline & Frequency & Percentage (\%) \\
\hline Discordance & 55 & 78.6 \\
\hline Minor discordance & 37 & 52.9 \\
\hline Major discordance & 18 & 25.7 \\
\hline Concordance & 15 & 21.4 \\
\hline
\end{tabular}

Lumbar spines showed osteoporosis in 14 (20.0\%), osteopenia in $25(35.7 \%)$ cases, and 31 (44.3\%) cases showed normal bone density (Figure 1). Hip bones showed osteoporosis in 55 (78.6\%) (Figure 2) and osteopenia in $15(21.4 \%)$ cases, while none showed normal bone density at this region. Comparison between the two sites showed that most of the osteoporosis was measured by hip bone score than by lumbar spine and the difference was significant. Among 70 patients $44.3 \%$ patients found normal by lumbar spine score but none is normal by hip score (Table 4).

In multivariate logistic regression analysis female sex $(\mathrm{p}=$ 0.34 , OR 1.95; CI: 0.43-9.99), age older than 60 years ( $\mathrm{p}=$ 0.23, OR 2.13; CI: 0.53-9.16) and BMI less than $30 \mathrm{~kg} / \mathrm{m} 2$ $(\mathrm{p}<0.001$, OR 71.56; CI: 7.85-1653.9) was identified as risk factors for T-score discordance (Table 5). 
Table 4 : Distribution of $T$ - scores according to WHO criteria between lumbar spine and hip bone and comparison $(n=70)$

\begin{tabular}{|l|c|c|c|c|c|}
\hline \multirow{2}{*}{ Classification of T score } & \multicolumn{2}{|c|}{ Lumbar spine score } & \multicolumn{2}{|c|}{ Hip bone score } & P value \\
\cline { 2 - 6 } & No. & $\%$ & No. & $\%$ & \\
\hline Osteoporosis $(\mathrm{T}=-2.5)$ & 14 & 20.0 & 55 & 78.6 & \multirow{3}{*}{} \\
\hline Osteopenia $(-2.5<\mathrm{T}=-1)$ & 25 & 35.7 & 15 & 21.4 & $<0.001^{*}$ \\
\hline Normal $(\mathbf{T}>-1)$ & 31 & 44.3 & 0 & 0 & \\
\hline Total & 70 & 100.0 & 70 & 100.0 & \\
\hline
\end{tabular}

Chi-square test was performed to compare between two sites.

Table 5 : Multivariate logistic regression analysis for risk factors of discordance $(n=70)$

\begin{tabular}{|c|c|c|c|c|}
\hline \multirow[b]{2}{*}{ Variables } & \multicolumn{2}{|c|}{ Discordance } & \multirow[b]{2}{*}{$\begin{array}{l}\text { Odd ratio } \\
\text { at } 95 \% \mathrm{CI}\end{array}$} & \multirow[b]{2}{*}{$\mathrm{p}$ value } \\
\hline & $\begin{array}{l}\text { Present } \\
(n=55) \\
\text { No. }(\%)\end{array}$ & $\begin{array}{c}\text { Absent } \\
(n=15) \\
\text { No. }(\%)\end{array}$ & & \\
\hline $\begin{array}{l}\text { Sex } \\
\quad \text { Male } \\
\quad \text { Female }\end{array}$ & $\begin{array}{l}18(32.7 \%) \\
37(67.3 \%)\end{array}$ & $\begin{array}{c}3(20.0 \%) \\
12(80.0 \%)\end{array}$ & $\begin{array}{c}1.95^{*} \\
(0.43-9.99)\end{array}$ & 0.34 \\
\hline $\begin{array}{l}\text { Age } \\
\begin{aligned}<60 \mathrm{yrs} \\
>60 \mathrm{yrs}\end{aligned} \\
\end{array}$ & $\begin{array}{l}24(43.6 \%) \\
31(56.4 \%)\end{array}$ & $\begin{array}{l}4(26.7 \%) \\
11(73.3 \%)\end{array}$ & $\begin{array}{c}2.13^{*} \\
(0.53-9.16)\end{array}$ & 0.23 \\
\hline $\begin{array}{l}\text { BMI } \\
\qquad \begin{aligned}<30 \mathrm{~kg} / \mathrm{m}^{2} \\
>30 \mathrm{~kg} / \mathrm{m}^{2}\end{aligned}\end{array}$ & $\begin{array}{c}46(83.6 \%) \\
9(16.4 \%)\end{array}$ & $\begin{array}{l}14(93 \%) \\
1(6.7 \%)\end{array}$ & $\begin{array}{c}71.56^{*} \\
(7.85-1653.9)\end{array}$ & $<0.001$ \\
\hline
\end{tabular}

*Indicates significant Odds ratio. Data are presented as frequency, percentage and odds ratio (95\%) Confidence Intervals in parentheses.

Most of the patients $78.6 \%$ had osteoporosis measured by hip bone score but only $20 \%$ measured osteoporosis by lumbar spine. $44.3 \%$ patients found normal by lumbar spine score but none is normal by hip bone score.

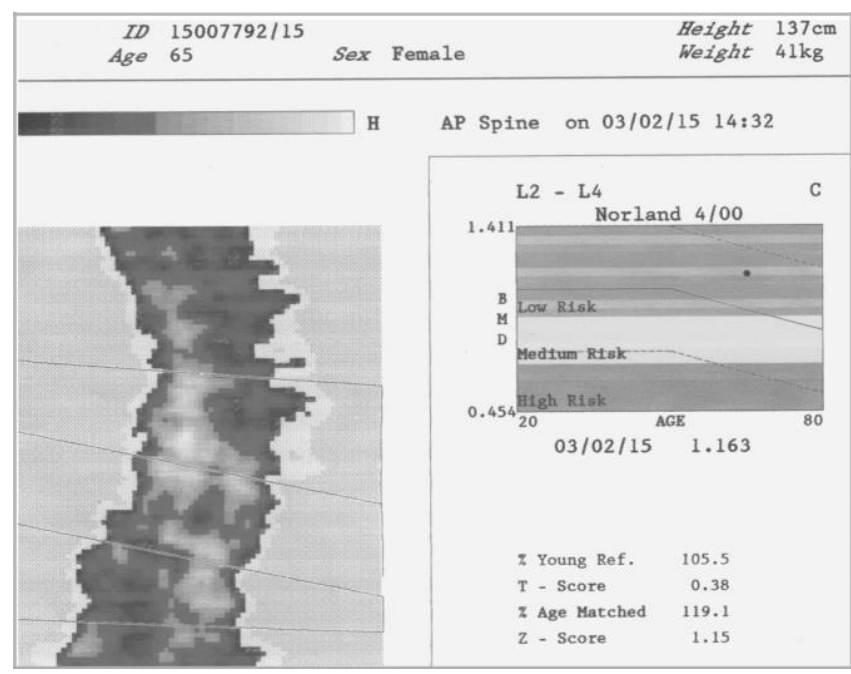

Figure 1: Anteroposterior lumbar spines show scoliosis and T-score 0.38, suggesting normal bone density.

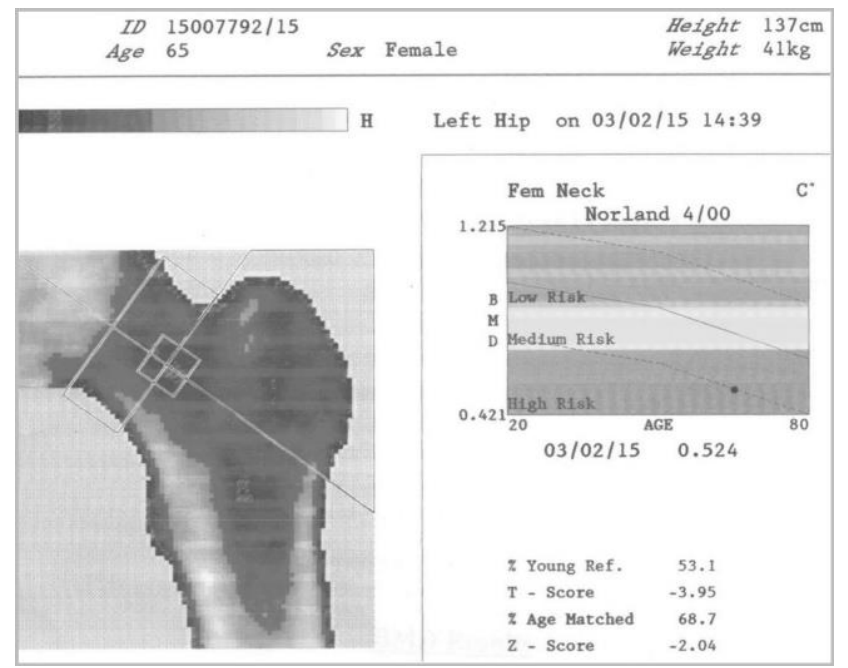

Figure 2: Hip bone (Neck femur) shows T-score 3.95, suggesting marked osteoporosis.

\section{DISCUSSION}

Discordance between lumbar spine and hip bone in DEXA scan is a common phenomenon and up to $45 \%$ of patient referred for DEXA scan may show diagnostic discordance (7). Depending upon the causes discordance has defined as physiologic discordance, patho-physiological discordance, anatomic discordance, artifactual discordance and technical discordance (6). The patho-physiological discordance is also called secondary discordance and occurs secondary to any disease or use of medicine like degenerative lumbar diseases. Degenerative lumbar spine disease is associated with development of vertebral osteophytes, facet degeneration, sclerosis of the inter-vertebral disc. These changes are responsible for falsely elevated lumbar spine $\mathrm{T}$-score and thereby elevated spinal BMD measurement in DEXA scan leading to discordance, the pathophysiological discordence (8).

In our small study population, scoliosis was found mostly in the female group. $\mathrm{T}$ score discordance was prevalent and present in $78.6 \%$ cases. Concordance was present in $21.4 \%$ cases. Minor and major discordance was observed in $52.9 \%$ and $25.7 \%$ cases respectively. Similar findings were observed and reported in a study on minor and major discordance between lumbar spine 
and hip DEXA scan. In another study conducted on lumbar scoliotic patients by Ioannis P. Pappou et al 2006, the spinal BMD exhibited discordantly high values despite the presence of significant hip osteoporosis (8). In our study osteoporosis was determined in $78.6 \%$ cases in hip DEXA and only 20.0 $\%$ cases in lumbar spine. Comparison between the lumbar spine and hip DEXA in scoliosis showed hip DEXA superior and more reliable or sensitive in the diagnosis of osteoporosis in the scoliosis patients. LeeRen Yeh et al (2004) and Ioannis P. Pappou et al (2006) stated similar finding in their reported studies $(8,9)$.

In our patients we looked for potential risk factors for T-score discordance. We considered old age, sex and BMI as possible risk factors for discordance and multivariate logistic regression analysis was done. In multivariate logistic regression analysis female sex ( $p$ $=0.34$, OR 1.95; CI: 0.43-9.99), age older than 60 years ( $\mathrm{p}=0.23$, OR 2.13; CI: 0.53-9.16) and BMI less than $30 \mathrm{~kg} / \mathrm{m} 2$ ( $\mathrm{p}<0.001$, OR 71.56; CI: 7.85-1653.9) was identified as risk factors for T-score discordance. We found $\mathrm{T}$-score discordance was more prevalent in female than male. In older age and patients having BMI less than $30 \mathrm{~kg} / \mathrm{m} 2$, the prevalence of discordance was more. Similarly female sex and old age were identified as risk factors in two studies. But in some studies BMI more than $30 \mathrm{Kg} / \mathrm{m} 2$ or obesity was identified as potential risk factor for $\mathrm{T}$ score discordance $(9,10)$. This finding is however not in agreement with our study result.

The high prevalence of discordance in lumbar scoliosis patient could induce problems or dilemma for the physician in diagnosis and management. Internationally it is recommended to use both spine and hip for DEXA scans and classify the patient based on the lowest $\mathrm{T}$ score value.

\section{CONCLUSION}

In lumbar scoliosis DEXA scan might show overestimation of lumbar BMD and high prevalence of discordance. The overestimation of lumbar spine may lead to diagnostic dilemma, whereas hip DEXA appears to be more reliable in these cases. In such cases it is in the jurisdiction of the physician to look for possible underlying causes of discordance of $\mathrm{T}$ score.

\section{REFERENCES}

1. Aziza Mounach, Asmaa Rezqi, Imad Ghozlani, Lahsen Achemlal, Ahmed Bezza, et al. Prevalence and Risk Factors of Discordance between Left- and Right-Hip Bone Mineral Density Using DXA. Volume 2012 , Article ID 617535, 6 pages. http://dx.doi.org/10.5402/2012/617535

2. Consensus Development Conference. Diagnosis, Prophylaxis and Treatment of Osteoporosis. Am J Med 1993; 94:646- 650.

3. World Health Organization. Assessment of Fracture Risk and its Application to Screening for Postmenopausal Osteoporosis. In: Technical Report Series 843. 1994.

4. Syed Z, Khan A. Bone Densitometry: Applications and Limitations. J Obstet Gynaecol Can 2002;24:476-84.

5. Faulkner KG, von Stetten E, Miller P. Discordance in Patient Classification Using T-scores. J Clin Densitom 1999;2:343-350.

6. Woodson G. Dual X-ray Absorptiometry T-score Concordance and Discordance between the Hip and Spine Measurement Sites. J Clin Densitom 2000; 3:319-24.

7. A. Mounach, MD, D.A. Mouinga Abayi, MD, M. Ghazi, MD, I. Ghozlani, MD, A. Nouijai, MD, L. Achemlal, MD et al. Discordance Between Hip and Spine Bone Mineral Density Measurement Using DXA: Prevalence and Risk Factors. J Sem Arthrit 2008; 04:1-5

8. Ioannis P. Pappou, Federico P. Girardi, Harvinder S. Sandhu, Hari K. Parvataneni, Frank P. Cammisa, et al. Discordantly High Spinal Bone Mineral Density Values in Patients With Adult Lumbar Scoliosis. SPINE 2006; 31(14)1614-20.

9. Lee-Ren Yeh, Clement K-H Chen, Ping-Hon Lai. Normal Bone Mineral Density in Anteroposterior, Lateral Spine and Hip of Chinese Men in Taiwan: Effect of Age Change, Body Weight and Height. J Chin Med Assoc 2004; 67:287-95.

10. Moayyeri A, Soltani A, Khaleghnejad Tabari N, Sadatsafavi M, Hossein-Neghad A, Larijani B. Discordance in Diagnosis of Osteoporosis Using Spine and Hip Bone Densitometry. BMC Endocrine Disorders 2005; 5:3 doi: 10.1186/ 1472-6823-5-3 